\title{
3 Research Square

\section{3 year old Female with Progressive Pseudorheumatoid Dysplasia misdiagnosed as Juvenile idiopathic arthritis}

\section{Anjumanara Anver Omar ( $\nabla$ anjumomar@yahoo.com )}

University of Nairobi School of Medicine https://orcid.org/0000-0001-5203-3689

\section{Salman Ahmed}

University of Nairobi College of Health Sciences

John Chris Rodrigues

Kenyatta National Hospital

Lawrence Owino

University of Nairobi College of Health Sciences

\section{Case Report}

Keywords: Progressive pseudorheumotoid dysplasia, WISP3 gene, Juvenile idiopathic arthritis, bone deformity

Posted Date: August 12th, 2020

DOI: https://doi.org/10.21203/rs.3.rs-53449/v1

License: (c) (i) This work is licensed under a Creative Commons Attribution 4.0 International License. Read Full License 


\section{Abstract}

Background: Juvenile idiopathic arthritis (JIA) is the most common chronic rheumatic disease in childhood and is of unknown aetiology. Progressive pseudorheumotoid dysplasia is a rare, autosomal recessively inherited, non-inflammatory musculoskeletal disorder caused by mutations occurring in the WISP3 gene. Joint cartilage is the primary site of involvement, leading to arthralgia, joint stiffness, contractures, enlargement of the epiphyses and metaphysis of the hand joints, spinal abnormalities, short stature, early osteoarthritis, and osteoporosis. The clinical features resemble juvenile idiopathic arthritis (JIA), and patients with PPD are usually misdiagnosed as JIA.

Case Presentation: A 13 year old female presented to the rheumatology clinic with history of joint pains, bone pains and bone deformity for 5 years. Weight and Height were below the 3 rd centiles. There was none tender swelling of metacarpophalangeal and interphalangeal joints and with scoliosis. Radiographs of the hands revealed widening of the epiphyses. With these findings Progressive Pseudorhematoid Dysplasia was suspected and genetic testing for WISP1, WISP2 and WISP3 was requested. A homozygous, likely pathogenic, variant was identified in WISP3 gene which confirmed our diagnosis.

Conclusion: Progressive Pseudorhematoid Dysplasia is a rare form of spondylo-epi-metaphyseal dysplasia and clinically misdiagnosed as Juvenile Idiopathic arthritis. It's important to consider PPD especially in patients with normal inflammatory markers who are being followed up for arthritis and not improving on anti-rheumatic intervention.

\section{Background}

Progressive pseudorheumatoid dysplasia (PPRD) is a joint disease that worsens over time. This condition is characterized by the degeneration of the articular cartilage which covers and protects the ends of bones (1).

PPRD has been estimated to occur in approximately 1 per million people in the United Kingdom. Though, this condition is thought to be more common in Turkey and the Middle East, its prevalence is unknown $(2,3)$. The condition in all regions is likely underdiagnosed because it is often misdiagnosed as juvenile idiopathic arthritis (4).

PPRD usually begins in childhood, between ages 3 and 8 years $(1,5)$. The first indications are usually an abnormal walking pattern, weakness and fatigue when active, and stiffness in the joints of the fingers and knees (6). Other signs and symptoms that develop over time include permanently bent fingers (camptodactyly), enlarged finger and knee joints (often mistaken as intraarticular swelling), and a reduced amount of space between the bones at the hip and knee joints. Hip pain is a common problem by adolescence. Affected individuals have flattened bones in the spine (platyspondyly) that are abnormally shaped (beaked), which leads to an abnormal front-to-back curvature of the spine (kyphosis) and a short torso (1). At birth, people with PPRD are of normal length, but by adulthood, they are usually shorter than their peers (6). 
This disorder is caused by a loss of function of the WISP3 gene (Wnt-1 inducible signaling pathway protein 3; MIM603400 ) encoded on chromosome 6q21.WISP3 is essential in maintaining cartilage integrity by regulating the expression of type II collagen and aggrecan in chondrocytes. Therefore, it is crucial for bone formation and maintaining cartilage (5-7). The clinical features are similar to those of juvenile idiopathic arthritis (JIA), and patients with PPD are usually misdiagnosed as JIA (4).

We present this case report of a 13 year old girl misdiagnosed as JIA

\section{Case Presentation}

We report a case of a 13 year old female who was referred to the rheumatology clinic with history of joint pains, bone pains and bone deformity for 7 years. She was born via spontaneous vaginal delivery without complication to consanguineous parents of Yemeni origin. She is the third born in her family. There is no history of joint disorders in the family. Joint pains and bone pains started at 6 years of age. This was followed by easy fatigability and swelling of the proximal (PIP) and distal (DIP) interphalengeal joints followed by the elbow joints. This was accompanied by pain in the left hip causing her to limp and finally inability to walk.

Initially at the age of 9 years she presented to the general practitioners with joint and bone pains. She was diagnosed with arthritis and treated with NSAIDS. However, her condition kept on deteriorating despite the NSAIDS and therefore referred to pediatric rheumatologist for further management. Her weight and height on presentation was <3rd percentile and upper- to lower body segment ratio was 1 .On examination patient was in fair general condition. She had marked prominence (swelling) of proximal (PIP) and distal (DIP) interphalangeal joints bilaterally which were non erythematous, and nontender (Figure 1). However there was limited mobility of the joints. Swelling of the knee and elbow joints bilaterally was also noted. She also had scoliosis on presentation. Laboratory tests done revealed a normal Erythrocyte sedimentation rate of $5 \mathrm{~mm}$ after one hour (reference 0-20mm); HLA-B27 was not detected which the antinuclear factor (ANA) and rheumatoid factor (RF) were both negative.

She was prepubertal at 13 years of age. Neurological examination did not reveal any abnormal findings. Radiographs of the hands and spine was requested.

\section{RADIOLOGICAL ASSESSMENT}

Radiology of the hands and spine was taken and revealed the following findings: Reduced joint space in the $3^{\text {rd }}$ and $4^{\text {th }}$ proximal interphalengeal joints with increased soft tissue density around the proximal interphalengeal joints (Fig 2) Radiology of the hip revealed reduction in the left femoral epiphysis, with associated mild sclerosis. There was presence of left femoral epiphyseal subchondral lucency, consistent with avascular necrosis of the left femoral head (Fig 3).Radiograph of the thoracolumbar spine revealed 
mild scoliosis with loss of height of the of the lower thoracic and upper lumber vertebral bodies. Anterosuperior endplate compression changes of multiple vertebrae were also noted (Fig 4)

\section{DIAGNOSIS}

In view of the clinical symptoms, laboratory and radiologic findings which were not in keeping with the diagnosis of Juvenile rheumatoid arthritis, Progressive Pseudorheumatoid Dysplasia was strongly suspected. Therefore, a genetic analysis of the WISP3 gene was carried out and a mutation in WISP3 gene was identified (Figure 5)

\section{Discussion And Conclusion}

Progressive pseudorheumatoid dysplasia (PPRD) is a skeletal dysplasia characterized by predominant involvement of articular cartilage with progressive joint stiffness and enlargement in the absence of inflammation. It starts between ages three and six years with the involvement of the interphalangeal joints as the initial clinical presentation (6). Over time, involvement of large joints and the spine causes significant joint contractures, gait abnormality, scoliosis or kyphosis which results in abnormal posture and significant morbidity (6). Likewise, our patient initially presented to the general practitioner with complaints of swelling of the proximal interphalengeal joints bilaterally. Like in our patient the condition in all regions is likely to be underdiagnosed because it is often misdiagnosed as juvenile idiopathic arthritis (JIA). PPRD is clearly differentiated from JRA by absence of inflammation, extra-skeletal manifestations and articular bone erosion. Moreover these patients do not respond to anti-rheumatic agents and therefore will not yield any clinical benefit. The radiological features are completely different from PPRD which include spondyloepiphyseal dysplasia with platyspondyly as an early finding, and the lack of destructive joint erosions $(8,9)$.

Although radiologic examination has high accuracy in the diagnosis of PPRD, the definitive diagnosis is established in a proband with identification of the characteristic radiologic findings and biallelic pathogenic variants in the WISP3 gene on molecular genetic testing (6). As the case in our patient a novel compound heterozygous mutation in the WISP3 variant c.746delT p. (Val249Glyfs*10) creating a premature stop codon 9 positions downstream was identified.

In conclusion patients presenting with musculoskeletal symptoms should be evaluated appropriately so that inappropriate therapy can be prevented and appropriate therapy started on time. Genetic testing and counseling should be offered to these families to plan for next generation.

\section{List Of Abbreviations}


ANA: Antinuclear antibody

JIA: Juvenile idiopathic arthritis

PIP: Proximal interphalengeal

DIP: distal interphalangeal

PPRD: Progressive pseudorheumatoid dysplasia

RF: Rheumatic factor

HLA-B27: Human Leucocyte Antigen

WISP3: WNT1-inducible signaling pathway protein 3

NSAIDS: Non steroid anti-inflammatory drugs

\section{Declarations}

Ethics approval and consent to participate: Written, informed consent was obtained from the affected individual and her legal guardians for both genetic analysis and publication of patients' photographs and imaging studies.

Consent for publication: Written, informed consent was obtained from the affected individual or their legal guardians for genetic analysis, publication of the case report and publication of patients' photographs and imaging studies.

Availability of data and materials: Data sharing is not applicable to this article as no datasets were generated or analyzed during the current study

Competing Interest: Authors declare that they have no competing interest

Funding: There was no funding to conduct this study

Authors' contributions: Anjumanara Omar and Lawrence Owino were major contributor in reviewing the literature and writing the manuscript and management of the patient.Salman Ahmed and John Chris Rodrigues had major roles in the radiological assessment of the patient. Centogene did the molecular analysis including the gene sequencing. All authors read and approved the final manuscript.

Acknowledgements: The authors wish to thank the patient and her family for their kind assistance. Author Information: Anjumanara Omar is the first author and Lawrence Owino is the senior author

\section{References}


1. Garcia Segarra N, Mittaz L, Campos-Xavier AB, Bartels CF, Tuysuz B, Alanay Y, Cimaz R, Cormier-Daire V, Di Rocco M, Duba HC, Elcioglu NH, Forzano F, Hospach T, Kilic E, KuemmerleDeschner JB, Mortier G, Mrusek S, Nampoothiri S, Obersztyn E, Pauli RM, Selicorni A, Tenconi R, Unger S, Utine GE, Wright $M$, Zabel B, Warman ML, Superti-Furga A, Bonafé L. The diagnostic challenge of progressive pseudorheumatoid dysplasia (PPRD): a review of clinical features,radiographic features, and WISP3 mutations in 63 affected individuals. Am J Med Genet C Semin Med Genet. 2012 Aug 15;160C(3):217-29. doi: 10.1002/ajmg.c.31333. Epub 2012 Jul 12. Review.Citation on PubMed: https://www.ncbi.nlm.nih.gov/pubmed/22791401

2. Giray E, Yağcı İ, Elçioğlu HN. Progressive pseudorheumotoid dysplasia: A presentation of four cases with slow and rapid progression and effects of early rehabilitation program. Turk J Phys Med Rehabil. 2019;65(3):290-297. Published 2019 Jan 29. doi:10.5606/tftrd.2019.2694

3. Balci S, Aypar E, Kasapçopur O, Tüysüz B, Arisoy N. An eleven-year-old female Turkish patient with progressive pseudorheumatoid dysplasia mimicking juvenile idiopathic arthritis. Clin Exp Rheumatol 2001;19:759.

4. Adak B, Tekeoğlu I, Sakarya ME, Uğraş S. Progressive pseudorheumatoid chondrodysplasia: a hereditary disorder simulating rheumatoid arthritis. Clin Rheumatol 1998;17:343-5.

5. Hu, Q., Liu, J., Wang, Y. et al. Delayed-onset of progressive pseudorheumatoid dysplasia in a Chinese adult with a novel compound WISP3 mutation: a case report. BMC Med Genet 18, 149 (2017). https://doi.org/10.1186/s12881-017-0507-3

6. Bhavani GSL, Shah H, Shukla A, et al. Progressive Pseudorheumatoid Dysplasia. 2015 Nov 25. In: Adam MP, Ardinger HH, Pagon RA, et al., editors. GeneReviews ${ }^{\circledR}$ [Internet]. Seattle (WA): University of Washington, Seattle; 1993-2020. Available from: https://www.ncbi.nlm.nih.gov/books/NBK327267/

7. ElianeChouery,SandraCorbani,JaleleddineDahmen,LeilaZouari,MoezGribaa,NadiaLeban,JemniBen Chibani,GérardLefranc,AliSaad,AmelHaj Khelil,AndoniUrtizberea,AndréMégarbané. Progressive pseudorheumatoid dysplasia in North and West Africa: Clinical description in ten patients with mutations of WISP3. Egyptian Journal of Medical Human Genetics Volume 18, Issue 3, July 2017, Pages 299-303. https://doi.org/10.1016/j.ejmhg.2016.11.004 
8. Taspinar O, Kelesoglu F, Keskin Y, Uludag M. Progressive Pseudorheumatoid Dysplasia Misdiagnosed as Seronegative Juvenile Idiopathic Arthritis. Ethiop J Health Sci. 2016;26(4):397-400.

doi:10.4314/ejhs.v26i4.12

9. Geetha Wickrematilake. Progressive Pseudorheumatoid Dysplasia or JIA? Case Reports in Rheumatology / 2017 / Volume 2017 |Article ID 1609247 | 3 pages | https://doi.org/10.1155/2017/1609247

\section{Figures}
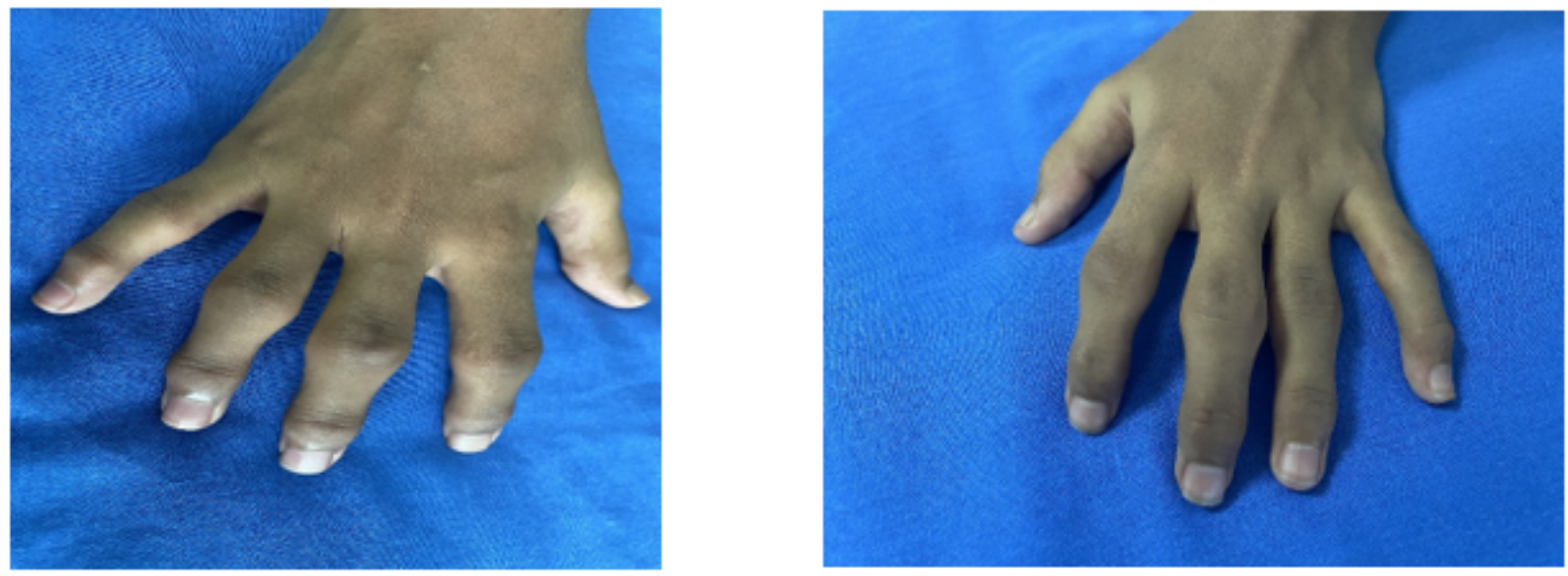

\section{Figure 1}

Swelling of the proximal and distal interphalengeal joints.

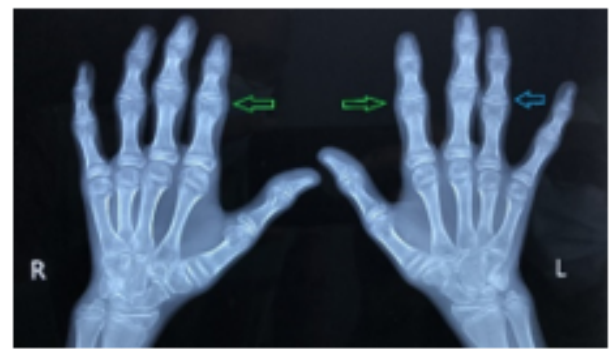

Figure 2

Reduced joint space 3rd and 4th interphalengeal joints 


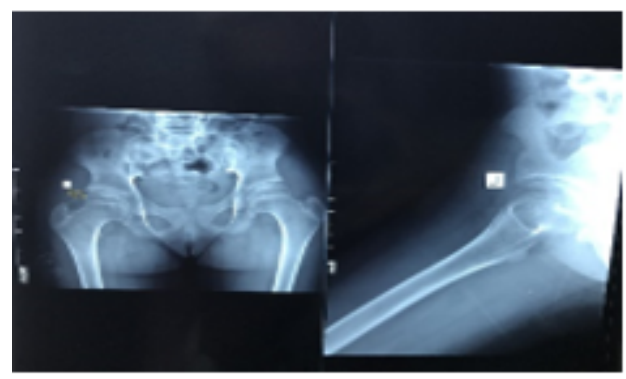

\section{Figure 3}

Fig 3: Reduction in left femoral epiphysis, with sclerosis

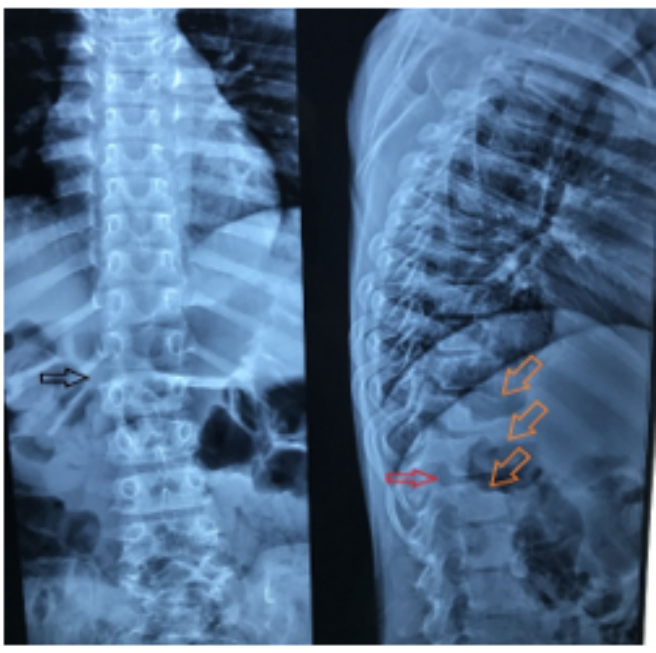

\section{Figure 4}

Antero-Superior endplate compression of the vertebra

\begin{tabular}{|c|c|c|c|c|c|c|c|}
\hline GENE & $\begin{array}{l}\text { VARIANT } \\
\text { COORDINATES }\end{array}$ & $\begin{array}{l}\text { AMINO ACID } \\
\text { CHANGE }\end{array}$ & $\begin{array}{l}\text { SNP } \\
\text { IDENTFIER }\end{array}$ & ZYGosity & $\begin{array}{l}\text { IN SIUICO } \\
\text { PARAMETERS }\end{array}$ & $\begin{array}{l}\text { ALLELE } \\
\text { FREQUENCIES** }\end{array}$ & $\begin{array}{c}\text { TYPE AND } \\
\text { CLASSIFICATION*.. }\end{array}$ \\
\hline WISP3 & NM_198239.1:c.746derT & p. Val249/s & N/A & homazy gous & $\begin{array}{c}\text { PolyPher: N/A } \\
\text { Align-GVGD: N/A } \\
\text { SIFT: N/A } \\
\text { MutationTaster: N/A } \\
\text { Conservation_nt: } \\
\text { Conservation_aa: }\end{array}$ & $\begin{array}{c}\text { GnomAD: - } \\
\text { 1K Genome:- } \\
\text { ESP: :- } \\
\text { CenoMD: - }\end{array}$ & $\begin{array}{l}\text { Frameshift } \\
\text { Likely Pathogenic } \\
\text { (class 2) }\end{array}$ \\
\hline
\end{tabular}

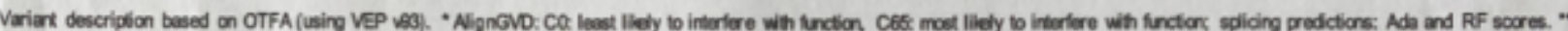

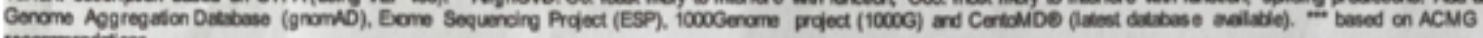
recormendations.

\section{Figure 5}

Mutation in the WISP3 gene 